\title{
Effect of Pile Orientation on the Shear Strength of Stitched Foam Sandwich Panel
}

\author{
Ramraj Santhanakrishnan ${ }^{a}{ }^{\mathbb{D}}$, Narayanan Kavitha ${ }^{a}$, Meenakshi Sundaram $^{a}$, \\ Pappakudi Srinivasan Venkatanarayanan ${ }^{a}$
}

${ }^{a}$ Hindustan University, Padur, Chennai 600016, Tamil Nadu, India

Received: December 18, 2017; Revised: June 15, 2018; Accepted: August 05, 2018

\begin{abstract}
Stitched foam sandwich panel is a newly developed sandwich structure used in various structural applications. The sandwich skins are made of glass-fiber/epoxy-matrix composite; their interior layers are connected with glass yarn called piles. This paper investigates the effect of pile orientation on the shear strength of stitched foam sandwich panel. Four types of pile orientation are used; $90^{\circ}, 45^{\circ}, 90$ $\mathrm{o} / 45^{\circ}$ and $90^{\circ} / 45^{\circ} / 90^{\circ}$. The results are compared with a non-stitched sandwich panel. From the results of the core shear test, it is observed that the panels with $90^{\circ} / 45^{\circ} / 90^{\circ}$ orientation proved to be strongest among all.
\end{abstract}

Keywords: Glass yarn, Stitched foam sandwich panel, Pile orientation.

\section{Introduction}

One of the most important advantages of the sandwich construction is high stiffness to weight ratio. The in-plane properties of the face sheet can be greatly increased by changing the orientation of the fiber direction, whereas out of plane properties are dependent on the resin. If the resin absorption is not uniform between the layers of the face sheets there is a possibility of delamination in between the layers. One of the methods to improve the out of plane properties of the face sheets is stitched through its thickness as given by Geon et al. ${ }^{1}$. Due to the high retention of in plane properties and increased resistance to delamination growth, stitched composites find application in structural applications including stiffened wing structure for commercial aircraft have been described by Sharma et al. ${ }^{2}$. Some of the factors that contribute to the failure of the sandwich panels are delamination/debonding, shear core failure, face wrinkling and buckling was discussed by Jack R Vinson ${ }^{3}$. This problem can be minimized by stitching the sandwich panel through its thickness. In order to evaluate the effect of stitching the detailed experimental work was carried out on sandwich panels and stitched foam sandwich panels.

Daniel $^{4}$ investigated the effective stiffness of throughthe-thickness Kevlar stitches in delaminated carbon/epoxy composites under out-of-plane tensile and shear loading. Lascoup et al. ${ }^{5}$ studied the mechanical characterisation (bending, shear and compression) of sandwich structures by stitching through its thickness. The study showed the impact of the inter-laminar shearing which tends to break the connection between the core and skin is reduced by stitching. This reinforcement increases the mechanical properties in the thickness direction and overcome the principal disadvantages of sandwich construction. Parambal Singh et al. ${ }^{6}$, in their study conducted on performance of stitched sandwich structures, It has been concluded that the initial failure load and core shear stress of $30^{\circ}$ pile orientations is higher than $90^{\circ}$ pile orientation. Engin M..Reis et al..$^{7}$ studied the effect of shear properties on the influence of through thickness and density.

Zhihua $\mathrm{Wu}$ et al. $^{8}$ studied the shear performance of integrated 3D composite sandwich structures and from the result it was observed that the shear properties of the integrated 3D composite sandwich structure were better than the conventional sandwich structures. Potluri et al. ${ }^{9}$ developed stitch bonded sandwich structures using commercial close cellular cores with woven broad cloth. Modified lock stitch method was adopted for stitching shown in Figure1. Failure loads of the specimens were studied by varying stitch pitch distance. The results show the debonding area is less for lesser stitch density specimens. Figure 2 shows multiple needle sewing machine in which the knots linking needle and bobbin threads are formed at one surface of the laminate to minimize the in plane fiber distortion. Pre-drilled sandwich core is placed in between the glass fabric face sheet. The multiple needles with Kevlar yarn are inserted through the thickness of the face sheet and core. At the bottom of the panel a loop is formed. By using looper the lock thread is inserted with the help of raiper.

Designing the sandwich structure to with stand the shear loading remains an important problem. The problem is more critical when lower stiffness foam cores subjected to high shear loading. The core first fails under shear because the weakest component of the sandwich construction is the core (assuming perfect contact between the foam core and the skin). Therefore, the most important aspects of the structural behaviour of the sandwich panel are the shear deformable core. So, the aim of the experiment is to determine the core shear modulus of the sandwich construction with and without 


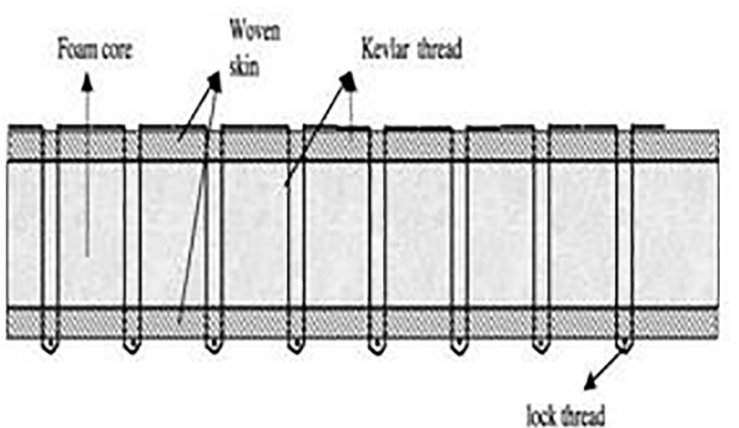

Figure 1. Illustration of modified lock stitch method used in stitch bonded sandwich constructions [Potluri et $a l^{9}$ ].

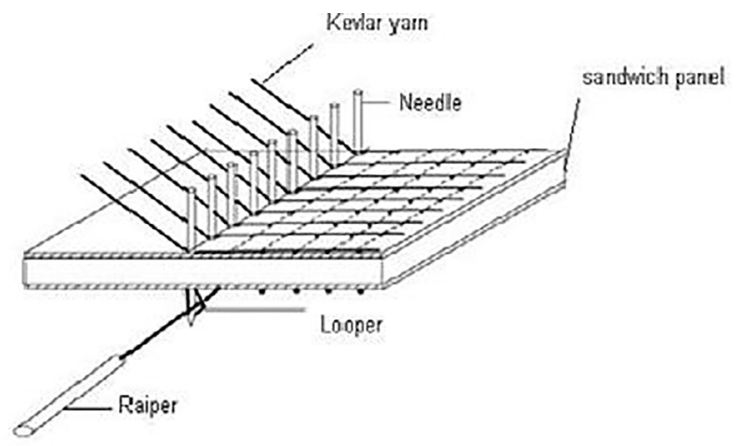

Figure 2. Illustration of multiple needle sewing machine for sandwich composite structures Potluri et al ${ }^{9}$.

stitching. The shear response of the sandwich panel with polyvinylchloride (PVC) was analysed.

\section{Experiment Method}

\subsection{Materials and manufacturer}

The core material selected for this study was Divinycell closed-cell ' $\mathrm{H}$ 'TM (manufactured by DIAB core, Sweden) grade foam core $\left(\right.$ density $=80 \mathrm{~kg} / \mathrm{m}^{3}$, thickness $=10 \mathrm{~mm}$, Shear strength $=1.15 \mathrm{MPa})^{10}$. This foam core was chosen because of its superior fatigue and impact resistance, damage tolerance, light weight and excellent cost effectiveness. The core material used in this study can be used for the vast majority of composite applications where both hand laminating and closed moulding process such as infusion is employed. Woven glass fabric of weight $320 \mathrm{~g} / \mathrm{m}^{2}$ with thickness of 10 mils woven open form saline treated E-glass ${ }^{\mathrm{TM}}$ (manufactured by FRP services, Japan, density $-2.55 \mathrm{~g} / \mathrm{m}^{3}$, Youngs modulus $=80 \mathrm{GPa}$ ) fabric cloth $^{11}$ was used as face sheets. The open form cloth was selected for this work as the resin is impregnated into the next layer of cloth easily when compared to closed form cloth. The properties of E-glass cloth are high stiffness, high strength to weight ratio, non-flammable, resistant to heat, good chemical resistance, relatively insensitive to moisture and good electrical insulation. Yarn twisted in one direction is called single yarn, and those twisted to the right and left are called S-twisted yarn and Z-twisted yarn respectively. Several single yarns twisted together are called as plied yarn. Single and plied yarns are used selectively according to the purpose. The resin used to produce composites was GY 257 epoxy resin cured with hardener $2963 \mathrm{CH}$, which is having good wetting ability and appropriate viscosity at room temperature. The ratio of the resin to hardener is 100:45. Santhanakrishnan et al. ${ }^{12}$ developed a stitching machine shown in Figure 3, which is used to stitch the sandwich panel at different pile orientation. Modified lock stitch method was adopted for stitching. Figure 4 and 5 shows the front and top view of the stitching machine. Figure 6 shows multiple needles used for stitching. Pre-drilled sandwich core is placed in between the two face sheets (top and bottom) and is kept in between the slotted plates as shown in the Figure 3. The

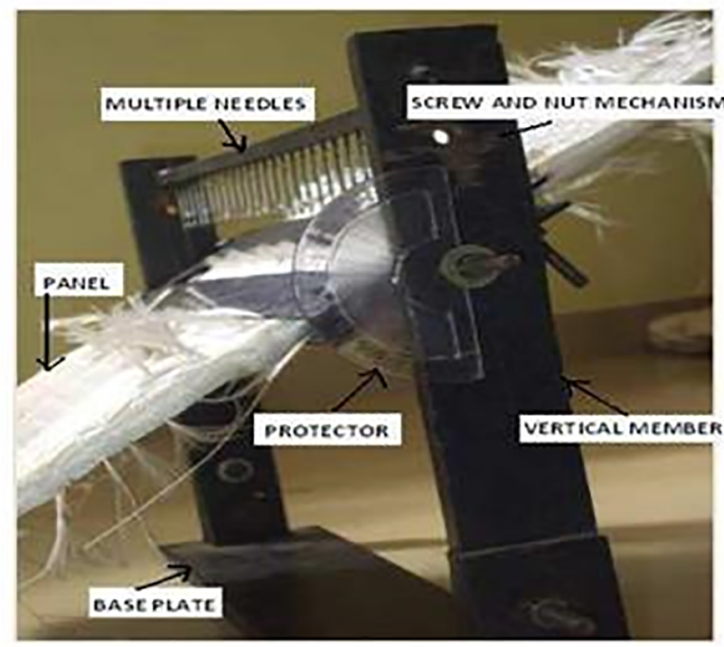

Figure 3. Illustration of stitching machine for sandwich composite structures [Santhanakrishnan et al. ${ }^{12}$.

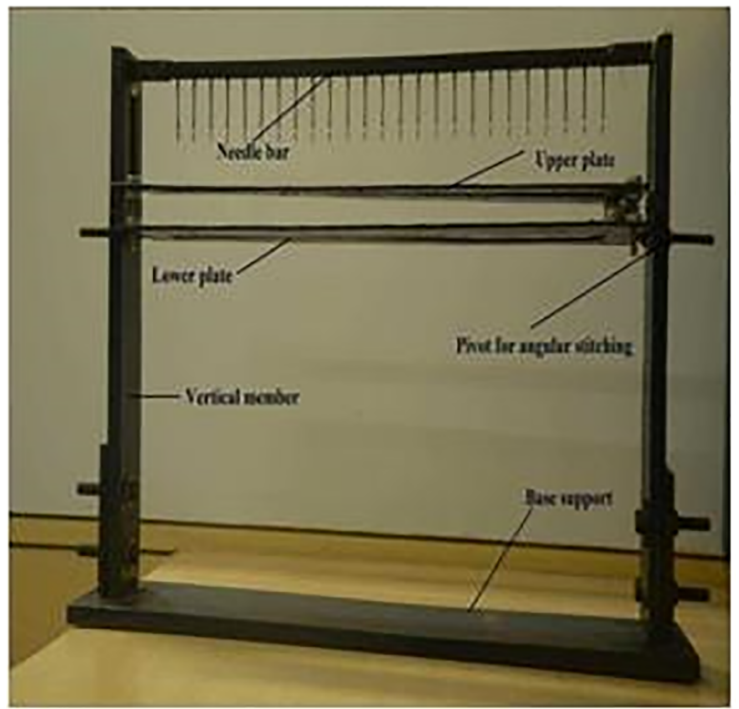

Figure 4. Front View of the Stitching Machine. 


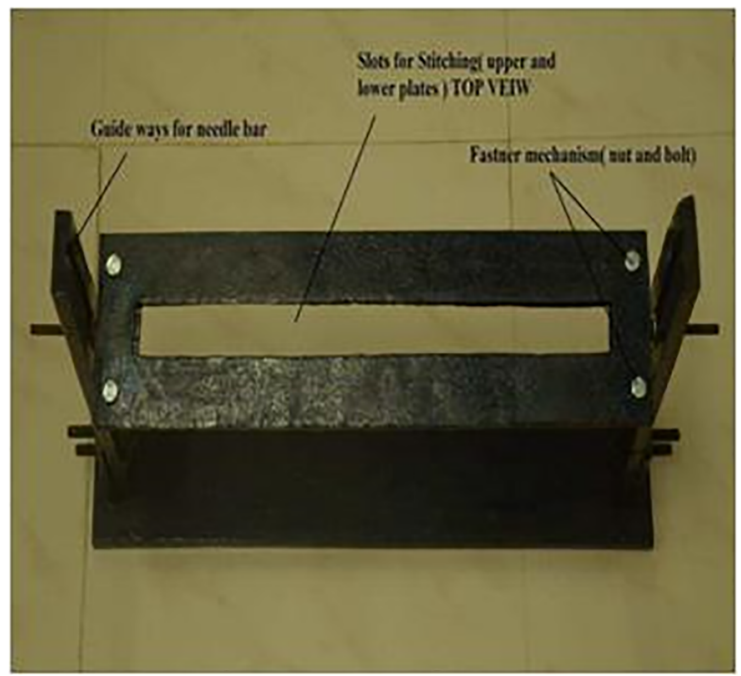

Figure 5. Top View of the Stitching Machine.

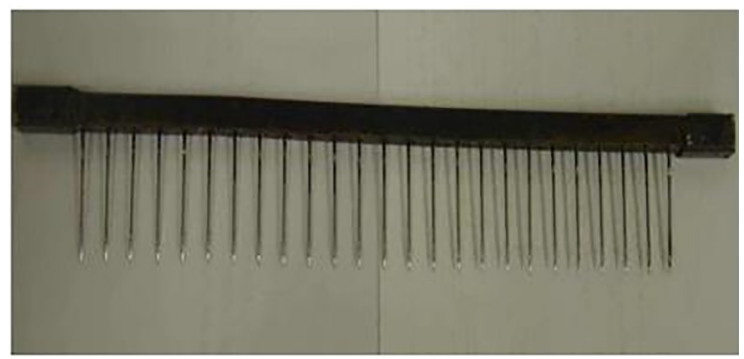

Figure 6. Multiple needles set up for stitching.

protector is fixed on the vertical member used for changing the orientation of the panel. Through the guide ways multiple needles are moved up and down. Glass yarns are inserted in to holes of the needles. The multiple needles with glass yarn are inserted through the thickness of the face sheet and core. At the bottom of the panel a loop is formed. By using looper the lock thread is inserted with the help of raiper.

Five different types of panels were manufactured in this work; unstitched sandwich panel and stitched sandwich panel at different pile orientation $\left(90^{\circ}, 45^{\circ}, 90^{\circ} / 45^{\circ}\right.$ and $90^{\circ} / 45^{\circ} / 90^{\circ}$ ). The $30 \times 30 \mathrm{~cm}$ panels were fabricated using the resin infusion process.

\section{Core Shear Testing}

Core shear testing was carried out according to ASTM C 273-61 standard "Standard Test Method for Shear Properties in Flatwise Plane of Flat Sandwich Constructions or Sandwich cores $^{13}$. This test determines the shear strength parallel to the plane of the sandwich and shearing modulus associated with in a plane normal to the facings. As per the standard test specimen width not less than twice the thickness and a length not less than 12 times the thickness. Dimensions of the specimens are length $(\mathrm{L})=200 \mathrm{~mm}$; width $(\mathrm{B})=50 \mathrm{~mm}$ and thickness $(\mathrm{T})=10.8 \mathrm{~mm}$.
Test specimens are shown in Figure 7. The main objective of this testing is to determine the interlaminar shear strength of stitched and unstitched sandwich specimens. Specimens are glued to the testing apparatus with the of epoxy adhesive having ahigh modulus of rigidity. The thickness of the plate varied according to the strength of sandwich, but the plate dimensions in such a way that that the line of action of the direct tensile or compressive force shall pass through the diagonally opposite corners of the sandwich, shown if Figure 8.The fixture set up for the core shear test is shown in Figure 9. Core shear testing was carried out at a constant rate of $0.5 \mathrm{~mm} / \mathrm{min}$. Load versus displacement plots were recorded during the test.

Five samples were carried out on each type of sandwich panel. Average values were taken for plotting the graph.

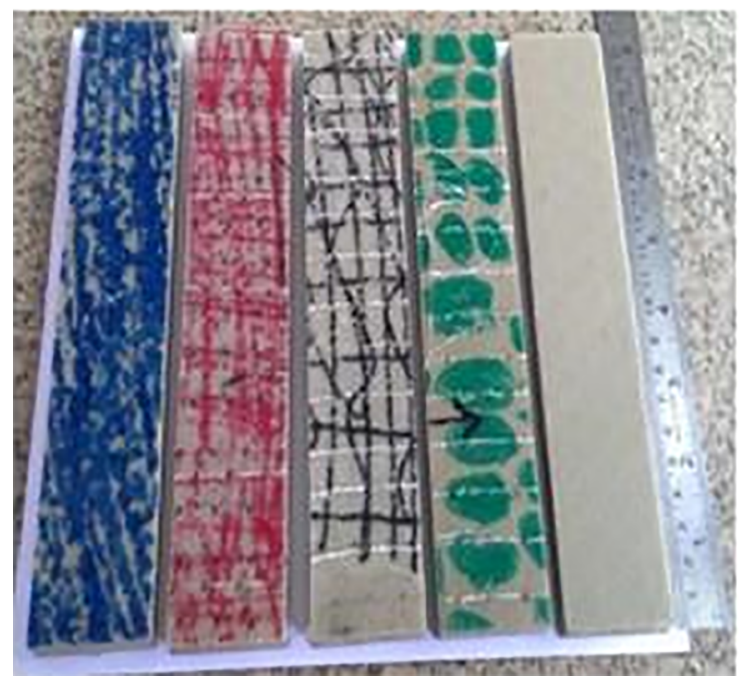

Figure 7. Specimens for core shear test.

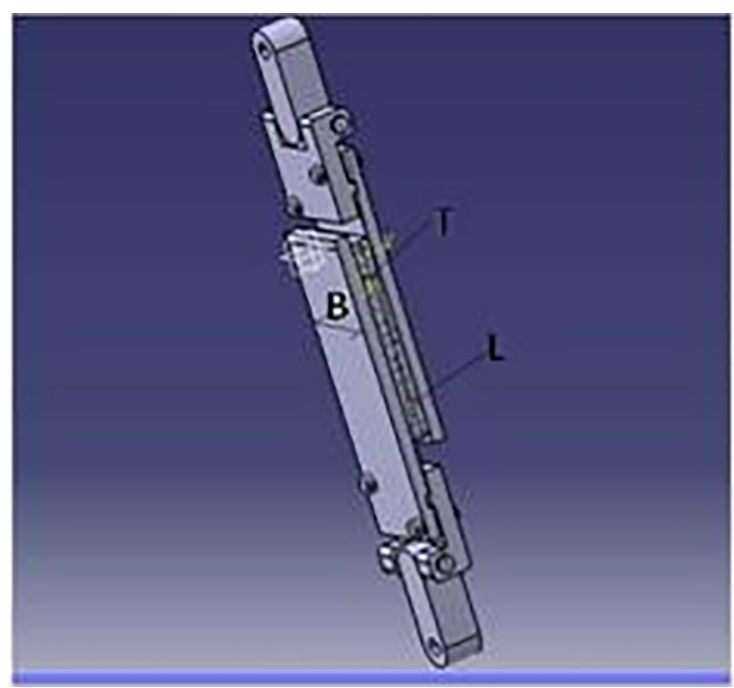

Figure 8. Core shear test schematization. 


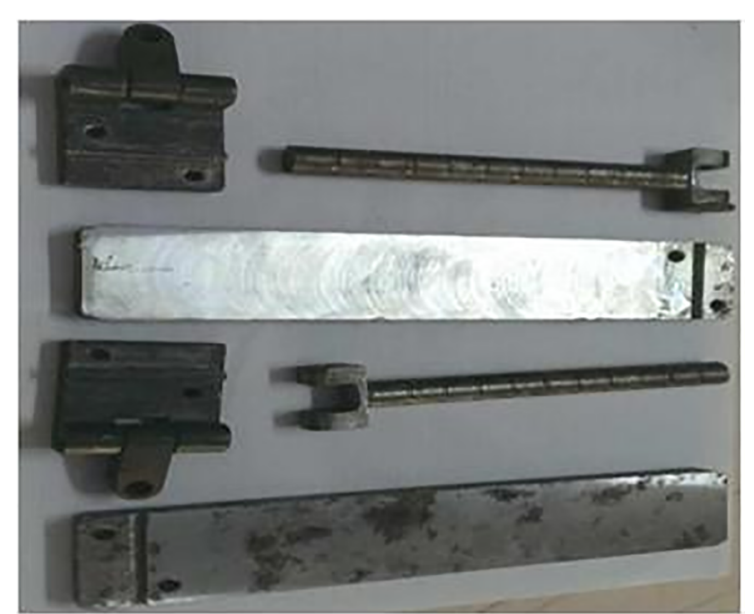

Figure 9. Core shear test fixture.

\section{Results and Discussion}

Core shear testing was carried out at a constant rate of $0.5 \mathrm{~mm} / \mathrm{min}$. Load versus Displacement plots were recorded during the test shown in Figure 10. Five tests were carried out on each type of sandwich panel. Core shear test results of the stitched and unstitched specimen are shown in Table 1. Shearing behaviour of the stitched foam sandwich panels differ from an unstitched sandwich panel by their brittle nature. The addition of stitches decreases the relative displacements of both skins in shearing conditions.

The shear modulus $\mathrm{G}_{\mathrm{xz}}$ is determined according to the following equations:

$$
G_{X Z}=\frac{P T}{B L \delta}
$$

Where $\mathrm{P}$ is the applied load $(\mathrm{N})$; $\mathrm{T}$, thickness $(\mathrm{mm})$; $\mathrm{B}$, width ( $\mathrm{mm})$; relative displacement $(\mathrm{mm})$; and $\mathrm{L}$ is the specimen length $(\mathrm{mm})$. The maximum stress is given by

$$
\tau_{X Z(\max )}=\frac{P_{\max }}{B L}
$$

Where $\tau_{\max }$ is the maximum load at specimen failure. For unstitched specimen load is increasing up to the maximum failure point and then specimen suddenly failed at the interface of the sandwich structures.

In all the stitched specimen the non-linearity observed up to the maximum failure load after that significantly load drop was measured. The maximum failure load was observed in $90^{\circ} / 45^{\circ} / 90^{\circ}$ specimens. The rigidity modulus of $90^{\circ} / 45^{\circ} / 90^{\circ}$ is $832.5 \%$ greater than the unstitched specimen, $85 \%$ greater than $90^{\circ}$ specimen, $45.19 \%$ greater than $45^{\circ}$ specimen and $18.6 \%$ greater than $90^{\circ} / 45^{\circ}$ specimen. The same phenomenon was reported by Parambal Singh et al. ${ }^{6}$.

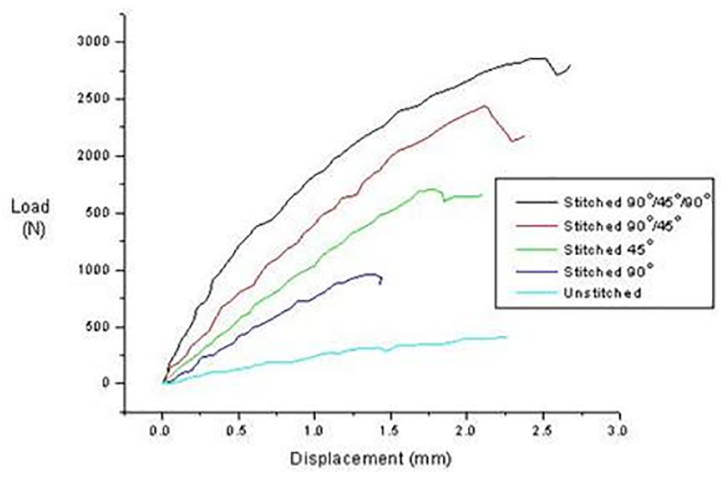

Figure 10. Core shear test results.

Table 1. Average shear strength and shear modulus (standard deviation in parenthesis)

\begin{tabular}{lccc}
\hline S1 No. & Sandwich Panel & $\begin{array}{c}\text { Ultimate Shear } \\
\text { Strength, } \\
\sigma_{\mathrm{s}}(\mathrm{KPa})\end{array}$ & Shear modulus \\
\hline 1 & Unstitched & $420(0.12)$ & $1.75(0.54)$ \\
2 & Stitched- 450 & $1686(0.32)$ & $11.24(0.43)$ \\
3 & Stitched- 900 & $963(0.41)$ & $8.78(0.39)$ \\
4 & Stitched- $900 / 450$ & $2443(0.33)$ & $13.75(0.47)$ \\
5 & Stitched- $900 / 45$ & $2844(0.32)$ & $16.32(0.51)$ \\
\hline
\end{tabular}

\subsection{Failure mode}

Katrzyna Grent et al..$^{14}$ observed that composites with foam core deformed plastically. The similar type of failure pattern was observed in unstitched specimen shown in figure 11. The failure of the unstitched sandwich specimens occurs in the foam core at an angle of $45^{\circ}$ to the direction of the load. This failure propagates to the skin through the skin core interface. In stitched specimen, this phenomenon was delayed because the out of plane property is improved by stitching through its thickness. In stitched foam sandwich panel foam does not play a significant role and the stitched control the ability of the material to resist the shear load. In $90^{\circ}$ stitched foam sandwich specimen the stitches break quickly one after the other when the damage starts which results in the fast degradation of the composite. In $45^{\circ}$ specimen the initial failure takes place at the point of anchoring of the stitches. This failure is carried on the weak zone of yarns due to abrupt change of orientations.

The stitches are subjected to a combined tension and shearing state of stress. In $90^{\circ} / 45^{\circ}$ specimens the rupture of stitches at the anchoring point but it delayed when compared to $45^{\circ}$ specimen. Initial crack is observed in $90^{\circ}$ yarn followed by $45^{\circ}$ yarn. In $90^{\circ} / 45^{\circ} / 90^{\circ}$ failure pattern is similar as like $90^{\circ} / 45^{\circ}$ pattern. The only difference is that the failure rate is very slow. Failure pattern of the specimens are shown in Figure $11-15$. 


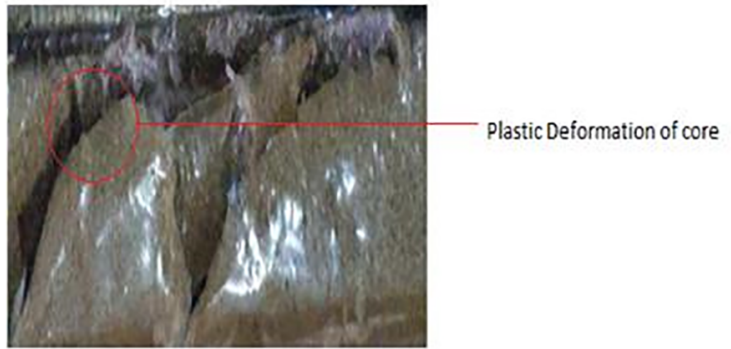

Figure 11. Unstitched specimen.

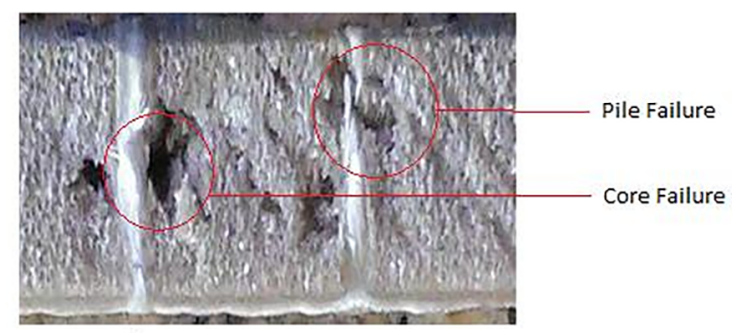

Figure 12. $90^{\circ}$ Stitched specimen.

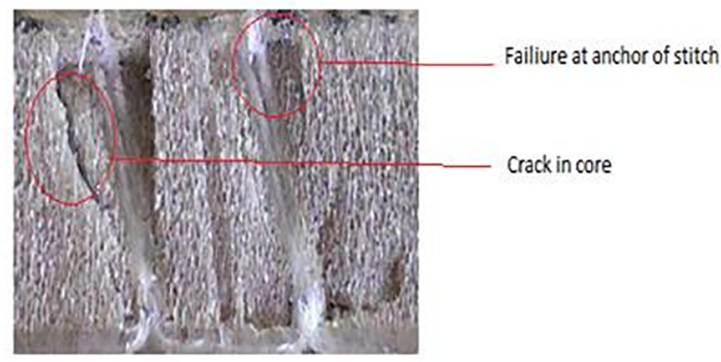

Figure $13.45^{\circ}$ Stitched specimen.

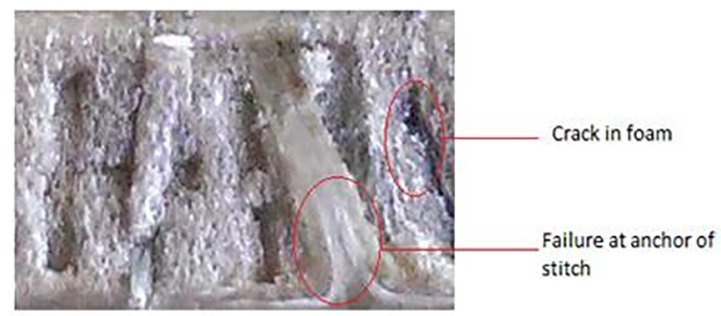

Figure 14. $90^{\circ} / 45^{\circ}$ Stiched specimen.

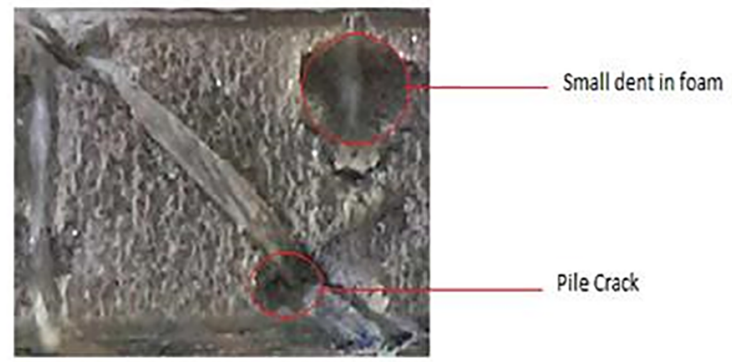

Figure $15.90^{\circ} / 45^{\circ} / 90^{\circ}$ Stitched specimen

\section{Conclusions}

The effects of pile orientation on the shear strength of stitched foam sandwich panel are carried out. Four types of pile orientation are used; $90^{\circ}, 45^{\circ}, 90^{\circ} / 45^{\circ}$ and $90^{\circ} / 45^{\circ} / 90^{\circ}$. The conclusions obtained from the result are as follows

1. Core shear test results show that the maximum failure load was observed in $90^{\circ} / 45^{\circ} / 90^{\circ}$ specimens. The rigidity modulus of $90^{\circ} / 45^{\circ} / 90^{\circ}$ is $832.5 \%$ greater than the unstitched specimen, $85 \%$ greater than $90^{\circ}$ specimen, $45.19 \%$ greater than $45^{\circ}$ specimen and $18.6 \%$ greater than $90^{\circ} / 45^{\circ}$ specimen.

2. From the failure mode study it has been seen that core damage is less for $90^{\circ} / 45^{\circ} / 90^{\circ}$ specimen as compared to the other specimens.

\section{References}

1. Lee GW, Choi JS, Lee SS, Park M, Kim J, Choe CR, etal. Mechanical properties and failure mechanism of the polymer composites with 3-dimensionally stitched woven fabric. Macromolecular Research. 2003;11(2):98-103.

2. Sharma SK, Sankar BV. Effects of Through-the-Thickness Stitching on Impact and Interlaminar Fracture Properties of Textile Graphite/ Epoxy Laminates. Haupton: NASA; 1995.

3. Vinson JR. The Behavior of Sandwich Structures of Isotropic and Composite Materials. Boca Raton: CRC Press; 1999.

4. Adams DO, Kessler JA, Nelson J, Bluth J, Kuramoto B. Development and Evaluation of Fracture Mechanics Test Methods for Sandwich Composites. In: Proceedings of the 2011 Federal Aviation Administration JAMS Technical Review Conference; 2011 Apr 20-21; San Diego, CA, USA.

5. Lascoup B, Aboura Z, Khellil K, Benzeggagh M, Maquet, J. On the interest of stitched sandwich panel. Compiègne: Dep GM-Polymers et composites BP; 2005.

6. Singh P, La Saponara V. Experimental Investigation on Performance of Angle Stitched sandwich Structures. In: 45thAIAA/ASME/ASCE/ AHS/ASC Structures, Structural Dynamics \& Materials Conference; 2004 Apr 19-22; Palm Springs, CA, USA.

7. Reis EM, Rizkalla SH. Material characteristics of 3-DFRP sandwich panels. Construction and Building Materials. 2008;22(6):1009-1018.

8. Wu Z, Xiao J, Zeng J, Liu J. Experimental on shear performance on integrated 3D composite sandwich structures. Journal of Sandwich Structures \& Materials. 2014;16(6):614-632.

9. Potluri P, Kusak E, Reddy TY. Novel stitch-bonded sandwich composite structures. Composite Structures. 2003;59(2):251-259.

10. Diab. Technical data. Available from: <www.diabgroup.com>. Access in: 14/11/2017.

11. FRP Services \& Company. Technical data. Available from: $<w w w$. frpservices.com>. Access in: 14/11/2017.

12. Santhanakrishnan R, Stanley D, Sanjeeviraja T, Stanley AJ. Effective Design Analysis of Fixture Development for Stitching a Sandwich Panels in an Aerospace Application. Applied Mechanics and Materials. 2014;592-594:1055-1059. 
13. ASTM International. ASTM C 273-61-Shear Properties in Flatwise Plane of Flat Sandwich Constructions or Sandwich Cores. West Conshohocken: ASTM International; 1988.
14. Grén K, Szatkowski P, Cholpak J. Characteristics of failure mechanism and shear strength of sandwich composites. Composite Theory and Practice. 2016;16(4):255-259. 